\title{
Energy scenarios and policies
}

Pablo Hevia-Koch, Jie Xu, Kaare Sandholt,2 Xue Han, ${ }^{2}$ Marie Münster ${ }^{3}$ and Sara Shapiro-Bengtsen³

'Danish Energy Agency; ${ }^{2}$ China National Renewable Energy Centre; ${ }^{3}$ Department of Technology, Management and Economics, Technical University of Denmark

\section{Introduction}

Climate concerns present a complex challenge for policy-makers, as decisions taken today can have lasting impacts on the future of the planet. This is particularly relevant when discussing the development of energy systems, where the pressing need to reduce greenhouse gas (GHG) emissions requires a deep decarbonization of the system. The climate targets of the Paris Agreement show that the green energy transition requires a novel scope and scale compared with past developments, passive measures no longer being enough to reach climate targets: the active decarbonisation of energy systems is required.

Due to the rapid pace of technological development, energy systems of the future will hardly resemble those that exist today at all, whether in terms of the technologies they use, the flexibility of their sources or the way they are operated. The development of new markets for energy and energy services, digitalization, novel technologies for energy generation and storage and the smarter operation of assets are only some of the drivers that will challenge policy-makers and planners into taking decisions requiring a fundamentally different approach compared to previous strategies for energy-system development.

In this context, the modelling of future scenarios has become an extremely significant tool in planning for the transition to renewable energy. In general, scenario analysis is a tool that helps in taking a long-term view in a world of great uncertainty by describing hypothetical possible futures and their corresponding pathways (Schwarz 2012) Beyond the characteristics they have in common, in the context of energy scenarios it is relevant to divide them into three categories: predictive, explorative, and anticipative (Dannemand and Rasmussen 2014). These different categories are linked to the research question that the scenarios attempt to answer, and therefore care must be taken to ensure an appropriate fit between the conclusions taken from a scenario and type of scenario used.

Predictive scenarios aim to describe the most plausible future, utilising the current context and observed trends. Predictive energy scenarios are often used when describing the expected evolution of an energy system if current policies are maintained in what is called a 'business-as-usual' scenario.
Explorative scenarios not only take into account the current context, they also aim to explore a series of possibly uncertain futures based on different assumptions, usually rooted in a qualitative but occasionally also quantitative assessment of different drivers. One example is exploring the effects of different possible policy measures on the evolution of the energy system and on climate, where the policies are determined by a qualitative assessment of possibilities, and the modelling provides a quantitative assessment of the effects of their implementation.

Anticipative scenarios (also called 'normative scenarios') work in a different direction, that is, by establishing a future definitive vision and working backwards to identify one or more pathways that can connect the existing context with the selected future scenario. As a result, they do not identify the effects of specific decisions today, but instead provide information on which decisions need to be taken to achieve a specific future state. In the field of energy, one of the most typical uses is to identify which policies need to be taken in order to achieve specific targets, for example, limiting global warming below $1.5^{\circ} \mathrm{C}$.

The main objective of long-term energy-planning models is to deliver support to strategic, operational and political decisions for future energy systems (IRENA 2019). In this manner, the effects of existing policies can be analysed, the effects of introducing new policies can be estimated, and new policies can be drafted in order to achieve a specific target.

\section{Policy ambitions for energy transition in China and Denmark}

\section{China}

China is focusing on building an energy system for the future, a development that will address the issues of energy security, energy efficiency and the promotion of a clean energy supply.

China has the ambition to develop an 'ecological civilization' as its main characteristic by 2035 to 2050. The concept of ecological civilization, which was written into the Chinese constitution in 2018, seeks to complement the three core dimensions of the concept of sustainable development - the environmental, economic and 
social dimensions - with specific features of Chinese political civilization, aspects of Chinese governance and core elements of the country's sustainable economic development agenda (Kuhn 2019).

China has committed itself to the Paris Agreement and the targets to avoid dangerous climate change by keeping global warming to well below $2^{\circ} \mathrm{C}$ and pursuing efforts to limit it to $1.5^{\circ} \mathrm{C}$. Its current Nationally Determined Contributions (NDCs) are committed to having $\mathrm{CO}_{2}$ emissions peak at the latest by 2030, to reach a non-fossil-fuel (i.e. renewables and nuclear) share of primary energy consumption of $20 \%$ (calculated by the special Chinese coal consumption substitution method (Lewis et al. 2015)), and to reach a reduction in carbon intensity of $60-65 \%$ by 2030 compared to 2005 (NDRC 2015). However, these targets are nowhere near sufficient to reach the goals of the Paris Agreement (Climate Action Tracker 2019).

At the $19^{\text {th }}$ National Congress of the Communist Party of China in 2017, President Xi Jinping confirmed that China would promote revolutions in energy production and energy consumption, in the development of energy technology and in forging a holistic energy system while at the same time strengthening international cooperation to ensure energy security, including access to energy resources (Jinping 2017). The country's plans emphasize shifting economic development from high growth to high-quality growth, a paradigm shift that also applies to the energy sector. Prompted by important milestones in 2020, 2035 and 2050, China aims to develop a 'clean, low-carbon, safe and efficient energy system' (The 13th Five-Year Plan for Economic and Social Development of the People's Republic of China 2015).

\section{Denmark}

Denmark has a history of a high level of ambition in de-fossilising its energy sector, with a heavy emphasis on building up a supply of renewable energy, aggressive energy-efficiency measures and a focus on developing specific technologies (as exemplified by its leading the way in developing offshore wind), while maintaining a constant view regarding sector coupling (Ropenus and Jacobsen 2015), that is, exploitation of the synergies created by integrating operations and planning across sectors (as, for example, heat and power). Despite this extensive history, the country has increased and renewed its ambitions to decarbonize Danish society further.

In 2019, Denmark passed a new Danish Climate Act (Aftale Om Klimalov 2019). This Act is the first legally binding piece of climate legislation, which introduces the goals of reducing $\mathrm{GHG}$ emissions by $70 \%$ by 2030 compared to 1990 and of achieving carbon neutrality by 2050 . This is an extremely ambitious strategy since, as of 2020, emissions have been reduced by $38 \%$ compared to the baseline of 1990 , meaning the remaining $32 \%$ need to be abated in the coming decade. Consequently, to achieve the Climate Act's targets, Denmark must reduce its carbon emissions at a rate much higher than yet seen.
According to analysis carried out by the Danish Council on Climate Change, this 70\% reduction in GHG emissions, while ambitious, is fully necessary if Denmark is to play its part in limiting the rise in global temperatures due to climate change to below 1.5 degrees C. In line with this necessity, it must be understood that such a broad and ambitious transition will come with associated economic costs. Nonetheless, analysis shows that, by implementing measures to achieve the $70 \% \mathrm{GHG}$ emissions reductions target in a cost-effective manner, the goal can be achieved while maintaining associated costs below 1\% of Denmark's GDP over the next ten years, compared to a 'business-as-usual' scenario.

\section{Energy scenarios for China}

China's energy planning is mainly related to the preparation of national and provincial five-year plans. The five-year plans set targets for the development of the energy system for the next five years, including specific targets for power-supply capacity, share of non-fossil fuels, etc. (National Energy Administration 2016). In a scenario context, the five-year energy plans work as a combination of a prediction and a (mandatory) anticipation (Nielsen and Karlsson 2007), for which the targets are minimum aspirations for the planned development.

The longer-term planning is dealt with by energy strategies, for example, (NDRC 2017). The energy strategy has a time horizon to 2030 and it is based on the same methodology as the five-year energy plan, with targets for key indicators and policy measures to implement the development. Compared with the five-year plan, the targets are less binding. Neither the five-year plans nor the energy strategies are completely supported by quantitative and comprehensive scenario analyses.

In general, sophisticated energy system-specific models for China are relatively few and recent (CNREC 2018, p. 346). These models have mainly been developed by universities, think-tanks, research institutes and energy sector-owned institutions (CNREC 2018, pp. 346-348; Lawrence Berkeley National Laboratory 2020).

\section{CREO scenarios: Methodology, assumptions, and main results}

Since 2011, the Energy Research Institute of the NDRC (ERI) and the China National Renewable Energy Centre (CNREC) have developed an energy model for a tool for holistic and quantitative analyses of the future development of the Chinese energy system. The models have been developed in close collaboration with the Danish Energy Agency, the US National Renewable Energy Laboratory, and other international partners.

The energy-system modelling tool consists of interlinked models covering the energy sector of Mainland China. The END-USE model, based on the Long-range Energy Alternatives Planning (LEAP) model, uses bottom-up analyses for Agriculture; Construction; Residential, Commercial and Government Buildings; Industries; and Transport. These sectors are further divided into 
relevant subsectors. The goal of the analysis is the primary energy demand of these sectors and subsectors. End-uses are driven by assumed developments in key activity levels specified for each subsector. These are physical or behavioural drivers specific to the subsector, or the subsector's economic value-added when no other driver is available. Transformation and resource activities, apart from district heating and power, are also covered by LEAP, including upstream refinery activity. Power and district-heating sectors are modelled in EDO (Electricity and District-heating Optimization).

The EDO model is a fundamental model of power and district-heating systems, built on the Balmorel model (Wiese et al. 2018).The power system is represented at the provincial level, taking the interprovincial grid constraints and expansion options into account. The model includes thermal power (including CHP), wind, solar (including CSP), hydro, power storage, heat boilers, heat-storage facilities, heat pumps, etc. It also covers demand-side flexibility in industry, options for charging electric vehicles and the option of a fully integrated coupling with the district-heating sector. The model can represent the dispatch in the Chinese power system on an hourly basis, taking into account the technical limitations of thermal power plants and interprovincial exchanges of power, as well as the dispatch in provincial, regional or national markets for power, based on least-cost marginal price optimization. Its key characteristics are related to the detailed representation of the variability of load and supply (e.g. from VRE sources), as well as flexibility and flexibility potentials, which can operate optimally and be deployed efficiently in capacity-expansion mode.

The results from the two models are combined in an integrated Excel-based tool, which provides an overall view of the energy system, combining fuel consumption from the power and heating systems from EDO with direct consumption by end-use sectors and other transformation sectors from LEAP (CNREC 2019, p. 14).

The energy model is used to prepare long-term energy scenarios to illustrate how China can transform its energy system into a clean, low-carbon, safe, energy-efficient, and cost-efficient system by 2050. These scenarios are analysed and presented in the yearly China Renewable Energy Outlook Report (CNREC 2019) from Energy Research Institute in the form of two main scenarios: the Stated Policies Scenarios and the Below $2^{\circ} \mathrm{C}$ Scenario.

The two scenarios represent two different scenario methodologies, the predictive and the anticipative (Nielsen and Karlsson 2007). The predictive scenario, called the 'Stated Policies Scenario', shows what the full and firm implementation of energy-sector and related policies announced in the $13^{\text {th }}$ Five-Year Plan and at the 19th Party Congress would look like in the long run. The central priority is the effort to build a clean, low-carbon, safe and efficient energy supply. The scenario also envisages the NDC climate emissions target peaking before 2030, the effects of the Blue-Sky Protection Plan, aspects of the Energy Production and Consumption Revolution Strategy, and the National Emissions Trading Scheme. In aiming to achieve the 2050 timeline, policy trends are extrapolated to set appropriate policy drivers (Zhongying and Sandholt 2019).

The anticipative 'Below $2^{\circ} \mathrm{C}$ Scenario' sets out the road for China to achieve its ambitious vision for an ecological civilization, a goal included in the Chinese constitution since 2018, and a clean, low-carbon, safe and efficient energy system, and to illustrate the role China could play in fulfilling the Paris Agreement. The main driver is a hard target for energy-related $\mathrm{CO}_{2}$ emissions through a strategy with renewable electricity, electrification, and sectoral transformation at its core. The target is set at a total of 200 million tons of energy-related $\mathrm{CO}_{2}$ emissions between 2018 and 2050.

The model results indicate a cost-effective pathway for the building of China's ecological civilization, driven by the large-scale deployment of a green power supply, wide improvements in energy efficiency to drive down overall energy demand and electrification as well as market reforms. These pillars of the energy revolution show that, according to the Below $2^{\circ} \mathrm{C}$ scenario, by 2050 the Chinese energy system may have a share of non-fossil fuels of $65 \%$, based on an electrification rate of $66 \%$, and up to $35 \%$ lower costs of power, while achieving a GDP in 2050 that is 4.2 times the GDP in 2018.

\section{Key policy measures for the energy transition in China} The scenario analysis in the China Renewable Energy Outlook 2019 (CNREC, 2019) sets out a clear threepoint strategy for the energy transition in China: 1) energy efficiency in end-use sectors; 2) electrification of key sectors (industry, transport, buildings); and 3) green energy supply, based on wind and solar power. This strategy is backed by the following key policy drivers:

- Promotion of renewable energy

- Coal control

- Promotion of energy-efficient measures

- Development of efficient power markets

- Power-system flexibility

- Carbon-pricing and efficient carbon control.

In the near term, the scenario analysis provides specific key recommendations to policy-makers to achieve a cost-effective energy transition that will not undermine the growth of the Chinese economy but will move away from the requirement for heavy subsidies for renewable energy. The 2019 version of the report highlights the need to go from an energy transition to an energy revoIution in order to build the ecological civilization, as well 


\section{Deep dive on waste as case}

The broader modelling of the Chinese energy system, as done in, for example, the China Renewable Energy Outlook, is capable of informing and being informed by deeper sector- or technology-specific analyses. One example is the analysis of waste management and energy generation carried out by Shapiro-Bengtsen et al. (2020)

Using waste fractions in modern energy facilities ad dresses waste management problems while providing energy services. For example, waste incineration reduces the need for landfill and contributes heat and power to the energy system. In respect of municipal solid waste (MSW), resource availability is the key to planning sufficient treatment capacity. China has gone from treating two thirds of collected MSW to treating $99 \%$ in just ten years (MoHURD, 2020). Some of this has been due to extensive investments in MSW incineration (MSWI) capacity, and China is well on its way to reaching its 2020 target of being able to incinerate 216 Mt of MSW nationally (NDRC \& MoHURD 2016). In 2018 China's MSWI capacity increased by $22 \%$ compared to the previous year, resulting in $45 \%$ of the collected $228 \mathrm{Mt}$ of MSW being incinerated (MoHURD 2020). However, investments in treatment capacity must be in line with the MSW to be treated. As these are long-term investments, longterm scenarios can help guide decisions. Even in the short term, there is a rist of provinces over-investing in MSWI capacity (Shapiro-Bengtsen et al. 2020)
Based on econometric analysis, Shapiro-Bengtsen et al. (2020) have projected mixed MSW and sorted food-waste development, using urban population and household income variables and setting out policy scenarios for the provinces extending to 2050

Increasing the sorting of waste is in line with the vision of China as an ecological civilization that makes efficient use of its resources. Sorting of MSW has already started in several cities, one of them being Shanghai, which has shown positive results (Huanbao 2020). With more food waste being sorted out of general waste, the levels of mixed MSW should decline, while the lower heating value (LHV) of mixed MSW should increase. The LHV of Chinese MSW is typically not high enough to sustain combustion and is therefore often co-fired with coal (Guo et al. 2018). If food waste were to be separated from mixed MSW, the need for co-firing with coal could be eliminated in five years (Shapiro-Bengtsen et al. 2020). These sorting schemes are therefore most relevant to include in planning for waste treatment capacity. More sorting puts pressure on other treatment facilities, as the sorted food waste should be treated in, for example, anaerobic digesters. If the extensive investments in MSWI capacity were to continue while China is increasing its resource efficiency, there is a risk of the country becoming locked-in to incineration, where sorting and specialized treatment of MSW fractions is not encouraged. as stressing the importance of the $14^{\text {th }}$ Five-Year Plan for 2021-2025 in accelerating the energy transition. Key recommendations for the $14^{\text {th }}$ Five-Year Plan period are:

- Set ambitious but realistic end-targets for the period: achieve 19\% of non-fossil energy by physical energy content, target a reduction of energy intensity of actual GDP by $21 \%$, and reduce $\mathrm{CO}_{2}$ emissions targeting a reduction of real $\mathrm{GDP} \mathrm{CO}_{2}$ intensities of $27 \%$.

- Leverage the cost reductions in wind and solar and scale up the pace of RE installations, including averaging annual additions of wind $53 \mathrm{GW}$ and solar $58 \mathrm{GW}$

- $\quad$ Ensure supporting RE policies, such as strong RE purchasing requirements, after the transition from subsidy to market prices. This could be achieved through an extension to the quota system or the facilitation of green PPAs.
- Internalize fossil fuel damage and/or abatement costs through the refined ETS mechanism.

- $\quad$ Pursue electrification with a focus on industry to reduce coal consumption and transport as a counter to the growing consumption of oil products.

- Avoid new coal-power plants and conduct orderly prioritized closures of inefficient plants and coal mines.

\section{Energy scenarios for Denmark}

Scenarios for different developments of the energy sector are a large part of the discussion of the future of the Danish energy sector and have been for many years. Scenario creation is not limited to government agencies, but also covers universities, organizations, independent counsels, sector partnerships and system operators providing their views on possible developments and recommendations for the entire energy sector in whole or in part. 
To create a baseline, and as part of Denmark's National Energy and Climate Plan to be submitted to the EU, the Danish Energy Agency annually prepares Denmark's Energy and Climate Outlook (DECO) with inter-ministerial support (Danish Energy Agency 2019). DECO consists of a technical assessment of Danish energy consumption and production, GHG emissions and their evolution up to 2030 from a frozen-policy perspective, that is, with no new policies being introduced. The purpose of DECO is to describe where Denmark stands and what challenges it faces in meeting its energy and climate obligations and policy targets. It is therefore an important planning tool in setting Danish energy and climate policy, as well as an important reference for assessing the impacts of new policy initiatives.

The overall picture shown in DECO 2020 was that, under the current set of policies, Denmark's GHG emissions are expected to be reduced by $44 \%$ in 2030 compared with the UN base year of 1990 .

However, the Danish Climate Act of 2019 (Aftale Om Klimalov 2019) sets a legally binding target to reduce GHG emissions by $70 \%$ by 2030 . As part of the Act, the Danish Council on Climate Change (an independent council) must present its professional assessment of whether the initiatives in the Danish government's annual Climate Action Plan are sufficient to reduce emissions (Danish Council on Climate Change 2020).

In its scenario for a 70\% reduction in GHG emissions, the Danish Council on Climate Change proposes a large package of sector-specific instruments paid for by a tax on GHG emissions. They also emphasize that
Denmark will not reach the $70 \%$ target without pursuing new and less well-known parts of the transition, specifying $\mathrm{CO}_{2}$ capture and storage, transport and agriculture as crucial in reaching the target.

As part of the Climate Action Plan, the government has created thirteen joint private-public climate partnerships, each representing a sector. The partnerships have now presented their initial recommendations to the Danish government on how to reach the 2030 target, which, as with other energy scenarios, is part of the ongoing political discussions for the Climate Action Plan.

Another relevant scenario analysis for Denmark is the Power and Gas Sector Outlook for Infrastructure Planning (PGSO-IP), prepared annually for use by Energinet (the Danish Power and Gas Transmission System Operator) as a basis for Energinet's planning of the Danish power and gas infrastructure. The PGSO-IP describes developments in the Danish energy system up to 2040. It is based on the best and, as far as possible, most robust hypothesis regarding developments in the energy system so as to safeguard against systematic under- as well as over-investment in the transmission grid, both of which would cost society more compared with the appropriate level of development (Danish Energy Agency and Energinet 2018).

The PGSO-IP describes how a long-term green transition might unfold, so it encompasses any additional measures needed for this development to happen. Therefore, while in the short term the methodology is similar to that utilized by DECO, the modelling of later years is based on Danish policy commitments and the targets laid down by the Danish Climate Act and Energy

\section{Deep dive into the gas case}

Large shares of variable renewable energy will need to be integrated to meet the targets of the Paris Agreement (IPCC 2019; UNFCC 2015). This integration will require increased flexibility in energy systems in terms of consumption, storage, transmission, and generation. To facilitate this, sector coupling between the power, heating, industry and transport sectors can assist in achieving low-cost solutions (Brown et al. 2018). A recent Danish research project, FutureGas, has analysed how Denmark can achieve ambitious climate targets in the future with sector-coupling of the above-mentioned sectors and with a focus on the role of gas (Münster et al. 2020). Three GHG emission scenarios have been analysed: Early Sprint reaching 375 Mt CO2eq by 2050, Marathon reaching 435 Mt CO2eq, and
Late Sprint reaching $708 \mathrm{Mt}$ CO2eq. All three scenarios achieve climate neutrality by 2050 and have similar costs for a system using between 400 and 650 PJ fuel per year (see Figure 1). The analysis was performed with the linear optimization model TIMES-DK (Balyk et al. 2019) for all GHG emissions in Denmark, and the results were soft-linked to Balmorel (Wiese et al. 2018) modelling the power, heating and process heat sectors in Denmark, as well as the power and district heating sectors in neighbouring countries, thus facilitating the optimization of investments and electricity transmission between countries. Both models perform least-cost optimization of investments and operation. Modelling assumptions can be found on the project's homepage (www.futuregas.dk). 


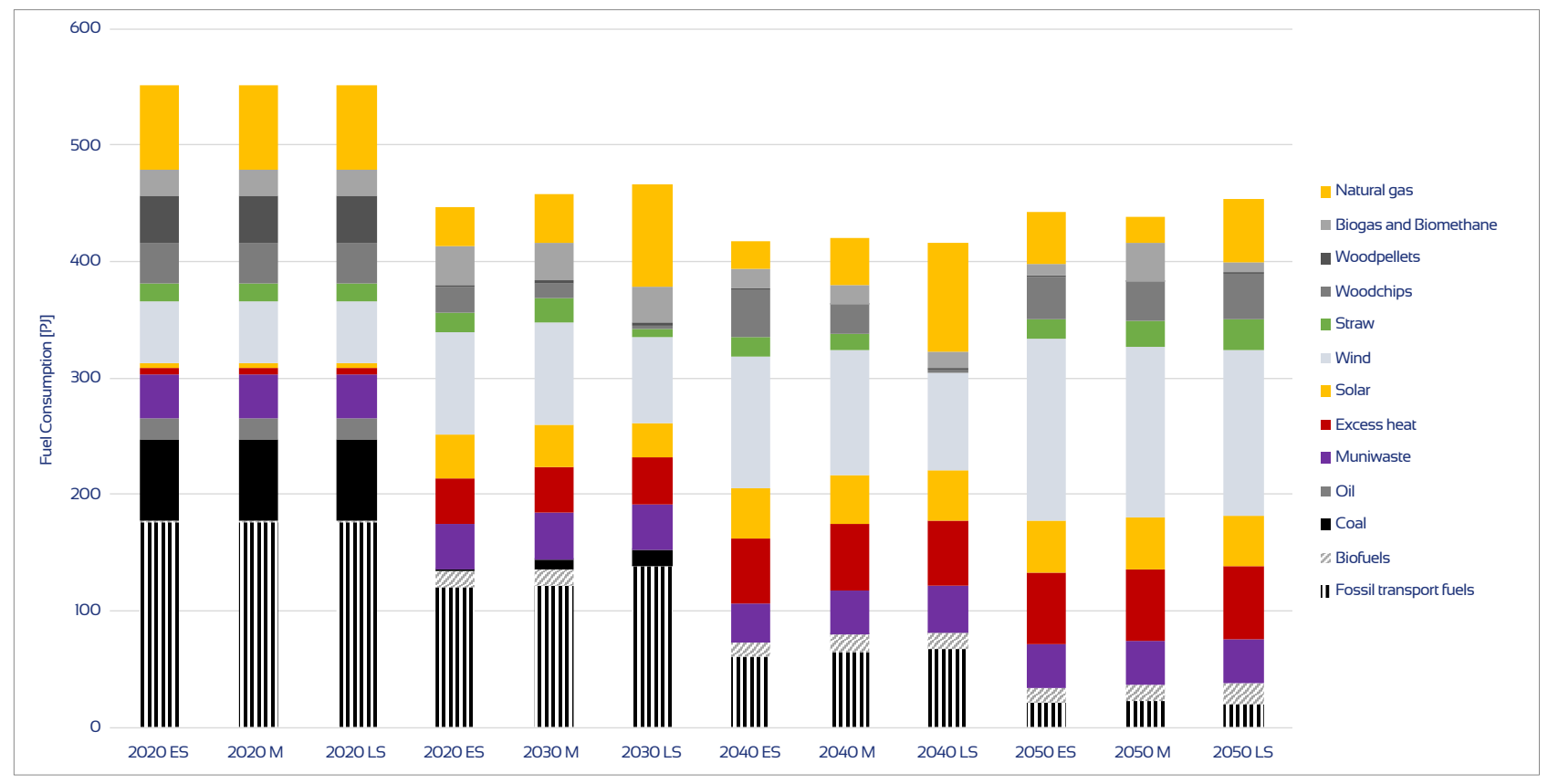

Figure 1 Potential fuel consumption in Denmark in 2020-2050 in the Early Sprint (ES), Marathon (M) and Late Sprint (LS) scenarios.

Agreement'. It is important to stress that the power and gas sector outlook has been prepared specifically to provide Energinet with the best possible basis for grid-planning, investment decisions, security of supply analyses, etc.

Broader scenarios are, once again, supported by deeper sector-specific analyses, such as the analysis carried out for the gas sector by the FutureGas project, described as an example in this chapter.

Figure 1 shows high shares of wind, which, together with solar PV, is the main source of power. District heating (which is assumed to continue constituting around two thirds of the demand for heating) is mainly produced from electricity (one third), excess heat from industry (one third) and the incineration of municipal solid waste (MSW) (one sixth). The last part of the demand for heating is supplied as individual heating, which is found to shift mainly towards electricity consumption using heat pumps. Process heat and transport are the two sectors that are most difficult to decarbonize. Process heat is mainly produced using gas and solid fuel. The transport sector shifts to electric and hybrid vehicles but also uses oil and biofuels for heavy transport. Substantial shares of electrofuels utilising hydrogen can be found in 2050 (around one third of demand) if production of fuels for international travel (aviation and ships) is included and imports of biomass and biofuels are restricted or expensive.

1 For example, Denmark's National Energy and Climate Plan related to the EU Climate and Energy Package and the Winter Energy Package.
For most scenarios, the demand for gas falls by 2050, but may increase in an intermediate period if low caps on CO2 and low fuel prices prevail as in the Late Sprint scenario. Gas is mainly used for process heat, but it also provides flexibility for the power and heating sectors. When including the option of carbon capture and storage, some natural gas is kept in the system, but local resources are available to cover the full consumption using green gases such as biomethane from upgraded biogas. In the transport sector, green gases are mainly used as a feedstock for the longer-term production of liquid bio-/electrofuels.

The scenario results illustrate how ambitious climate targets with high shares of wind and electrification and with low additional costs can be achieved if the synergy potentials available from sector coupling are utilized in smart energy systems linking the power, heating, industry and transport sectors.

\section{Key policy measures for the energy transition in Denmark}

On 22 June 2020, the Danish government announced the Climate Agreement on the Energy Sector and Industry (Klimaaftale for Energi Og Industri Mv. 2020, 2020), which sets out an initial set of specific policy initiatives to implement the targets laid down in the Danish Climate Act, with recommendations from the (Danish Council on Climate Change 2020).

Denmark will use two tracks to accomplish this goal:

1. The implementation track, where known and already commercially available measures and technologies see wider adaptation and use. 
2. The development track, where new technologies are developed and quickly implemented as soon as they fulfil expectations regarding their costs and effectiveness.

The implementation track will apply climate technologies to all sectors of the Danish economy. Previous climate strategies, as in most other countries, have focused on energy use and energy production. The new climate strategy aims to transform the methods currently used in transport, farming, industry and more by developing more effective policies to ensure the broad and swift application of existing solutions that have not yet been completely implemented. One of the major areas of transformation is agriculture, which has previously been ignored in climate strategies, but is expected to produce $25 \%$ of the accumulated GHG emissions in 2030 (Danish Energy Agency 2019).

The technological advances and improvements to processes to combat climate change are improving rapidly. These developments should not be ignored, but nor will Denmark place all its hopes in futuristic technology scenarios that may not ever bear fruit. Some examples of technologies being considered are the broad deployment of Power-to-X in conjunction with a dedicated energy-island project in the North Sea, as well as various energy-storage methods.

The strategy looks at technologies and methods that are in their commercial infancy, but which are likely to be implemented within the next decade. Quite possibly some of these will never be commercially viable, so the strategy takes this into account by suggesting more methods than needed and weighing them in terms of the probability of their implementation. Thus, the strategy can afford several of these technologies and tactics faltering without the $70 \%$ reduction goal being compromised.

A delicate balance must therefore be achieved between developing new promising technologies, ensuring the efficient deployment of existing solutions and retaining awareness of the social costs associated with the energy transition. As presented in the Climate Act (Klimaaftale for Energi Og Industri Mv. 2020, 2020), offshore wind will be a main technology, particularly in connection to the energy islands project described in the agreement. It is essential that, in planning the further siting and development of specific technologies such as offshore wind, social acceptance costs are considered as part of the planning exercise (Hevia-Koch 2018; Hevia-Koch and Klinge Jacobsen 2019).

\section{Comparison of and lessons learnt from sce- nario-planning and policy-making in China and Denmark}

'Long-term energy scenarios provide crucial guidance on energy transition pathways. These projections analyse the socioeconomic and environmental benefits of sustainable energy policies and investments. They can play a central role in informing short-term COVID-19 crisis responses, designing mid-term green recovery policies, and promoting long-term resilience, energy security, justice, job creation, and sustainability in the energy sector. Strengthening the capacity within governments to develop and understand energy scenarios aligned with the Paris Agreement is essential for better decision making'. This is one of the main findings from the UN report on the sustainable development goals in the time of Covid-19 (United Nations 2020).

Looking at scenario-planning in China and Denmark, it is clear that comprehensive energy system scenarios exist in both countries, but also that their respective governments do not use scenario-planning as a key policy-making instrument. The comprehensive scenario analyses are often carried out by universities, thinktanks and organizations outside government and are often used to inform policy-makers about development pathways, but in the actual decision-making, simpler analyses and predictions are used as basis for the decisions. While in Denmark, high-quality scenarios are used as part of the government analysis for policy development (Danish Energy Agency 2019), the potential for expanding the horizon and scope of these scenarios, as well as their relevance in the policy-making toolkit, is vast and of great relevance due to the high levels of ambition regarding climate and energy.

China and Denmark both have clear, long-term visions for a deep-energy transition, and both countries could benefit from a more advanced use of energy scenarios to explore possible development pathways and also to analyse the anticipated pathways to fulfil the long-term visions. Especially when the solutions include new technologies and system configurations which are still in the development phase, it would be useful to give more attention to different pathways with different assumptions regarding the pace of technological innovation.

Looking at the overall energy-policy strategy, China and Denmark have several similarities. In both countries, a sustainable policy strategy would include strong energy-efficiency measures in the end-use sectors, as well as strong measures to promote the electrification of industry, buildings (heating) and transport energy consumption and to transform the power supply into a green, low-carbon system based on renewable energy. As medium- and long-term strategies, the development of storage technologies and conversion technologies in a system context will be vital for the deep decarbonization of the energy system. Both countries will rely on markets as a decisive tool for policy implementation, including a well-functioning power market with support to system flexibility and system security

However, the two countries' implementation strategies would differ. Denmark is a small country within the EU, with excellent opportunities for power exchanges with neighbouring areas, while China's provinces are quite 
different regarding energy consumption and the availability of energy sources. A comparison between China and the EU would be more relevant regarding overall energy policy strategies, not only due to geography, but also with regard to the variety of resources and the different demographic profiles.
Close and long-term cooperation between China and Denmark in the field of energy policy and energy system analyses nevertheless provide an excellent platform for the further development and use of comprehensive energy system scenarios as a tool for policy-making, to the benefit for both countries.

\section{References}

Aftale om klimalov. (2019). Aftale om klimalov af 6. december 2019, mellem Regeringen (Socialdemokratiet), Venstre, Dansk Folkeparti, Radikale Venstre, Socialistisk Folkeparti, Enhedslisten, Det Konservative Folkeparti og Alternativet.

Balyk, O., Andersen, K. S., Dockweiler, S., Gargiulo, M., Karlsson, K., Næraa, R., Petrović, S., Tattini, J., Termansen, L. B., \& Venturini, G. (2019). TIMES-DK: Technology-rich multi-sectoral optimisation model of the Danish energy system. Energy Strategy Reviews, 23, 13-22. https://doi. org/10.1016/j.esr.2018.11.003

Brown, T., Schlachtberger, D., Kies, A., Schramm, S., \& Greiner, M. (2018). Synergies of sector coupling and transmission reinforcement in a cost-optimised, highly renewable European energy system. Energy, 160, 720-739. https:// doi.org/10.1016/j.energy.2018.06.222

Climate Action Tracker. (2019). China Climate Action Tracker. https://climateactiontracker.org/countries/china/

CNREC. (2018). China Renewable Energy Outlook 2018 http://boostre.cnrec.org.cn/wp-content/uploads/2018/11/ CREO2018-EN-final-1.pdf

CNREC. (2O19). China Renewable Energy Outlook 2019. http://boostre.cnrec.org.cn/wp-content/uploads/2020/O3/CREO-2019-EN-Final-20200418.pdf

Danish Council on Climate Change. (2020). Kendte veje og nye spor til 70 procents reduktion [Known paths and new tracks to 70 per cent reduction].

Danish Energy Agency. (2019). Denmark's Energy and Climate Outlook 2019

Danish Energy Agency, \& Energinet. (2018). Power and Gas Sector Outlook for Infrastructure Planning 2018.

Dannemand, P., \& Rasmussen, B. (2014). General rights Introduction to foresight and foresight processes in practice: note for the PhD course Strategic Foresight in Engineering Introduction to foresight and foresight processes in practice. http://projects.mcrit.com/esponfutures/documents/
Foresight methodology/Introduction to foresight and foresight processes in practice.pdf

Guo, Y., Glad, T., Zhong, Z., He, R., Tian, J., \& Chen, L. (2018) Environmental life-cycle assessment of municipal solid waste incineration stocks in Chinese industrial parks. Resources, Conservation and Recycling, 139, 387-395. https://doi.org/10.1016/j.resconrec.2018.05.018

Hevia-Koch, P. (2018). Economics of Wind Integration: An Acceptance Costs Approach [Technical University of Denmark]. www.sys.man.dtu.dk

Hevia-Koch, P., \& Klinge Jacobsen, H. (2O19). Comparing offshore and onshore wind development considering acceptance costs. Energy Policy, 125, 9-19. https://doi. org/10.1016/j.enpol.2018.10.019

Huanbao. (2020). 垃圾分类助干垃圾桶减量 [Garbage sorting helps reduce waste]. http://huanbao.bjx.com.cn/ news/20200116/1036930.shtml

\section{IPCC. (2019). Global Warming of $1.5^{\circ} \mathrm{C}$. An IPCC Special} Report on the impacts of global warming of $1.5^{\circ} \mathrm{C}$ above pre-industrial levels and related global greenhouse gas emission pathways, in the context of strengthening the global response to the threat of climate change.

IRENA. (2019). Long-term energy scenarios: Firstyear campaign findings. In LTES Campaign. / publications/2019/May/LTES-First-year-campaign-findings.

Jinping, X. (2017). Secure a Decisive Victory in Building a Moderately Prosperous Society in All Respects and Strive for the Great Success of Socialism with Chinese Characteristics for a New Era. Delivered at the 19th National Congress ofd the Communist Party of China.

Klimaaftale for energi og industri mv. 2020. (2020). Klimaaftale for energi og industri mv. 2020 af 22. juni 2020, mellem Regeringen (Socialdemokratiet), Venstre, Dansk Folkeparti, Radikale Venstre, Socialistisk Folkeparti, Enhedslisten, Det Konservative Folkeparti, Liberal Alliance og Alternativet. 
Kuhn, B. (2019). Ecological civilisation in China. Dialogue of Civilizations Research Institute. https://doc-research. org/2019/08/ecological-civilisation-china-berthold/

Lawrence Berkeley National Laboratory. (2020). China 2050 Demand Resources Energy Analysis Model (DREAM). https://china.lbl.gov/dream

Lewis, J. I., Fridley, D. G., Price, L. K., Lu, H., \& Romankiewicz, J. P. (2015). Understanding China's non-fossil energy targets. Science. https://doi.org/10.1126/science.aad1084

MoHURD. (2O2O). 2002-2018年城乡建设统计年鉴 [20022018 National urban statistics]. http://www.mohurd.gov.cn/ xytj/tjzljsxytjgb/jstjnj/wO2019012421874448602635000.zip

Münster, M., Morthorst, P. E., Bramstoft, R., Stryg, M., Aryal, N., Kofoed, M. V. W., Kvist, T., Ahlgren, E., Buchholz, S., \& Pisinger, D. (202O). Final FutureGas Report. www.futuregas.dk

National Energy Administration. (2016). 电力发展'十三五' 规划 (2016-2020年) [The 13th Five-Year Plan for Electric Power Development (2016-2020)]

NDRC. (2015). 强化应对气候变化行动一一中国国家自主贡献 [Enhanced Actions on Climate Change: China's Intended Nationally Determined Contributions]. https://www4. unfecc.int/sites/ndcstaging/PublishedDocuments/China First/China\%27s First NDC Submission.pdf

NDRC. (2017). Energy Supply and Consumption Revolution Strategy (2016-2030).

NDRC, \& MoHURD. (2O16). 十三五'全国城镇生活垃圾无害化 处理设施建设规划 [13th FYP for municipal solid waste treatment]. https://www.gov.cn/xinwen/2016-09/29/5113515/ files/3263ac47f16f4cecbbefObalcOd86039.pdf

Nielsen, S. K., \& Karlsson, K. (2007). Energy scenarios: a review of methods, uses and suggestions for improvement. In International Journal of Global Energy Issues (Vol. 27, Issue 3, pp. 302-322). Inderscience Publishers. https:// doi.org/10.1504/IJGEI.2007.014350
Ropenus, S., \& Jacobsen, H. (2O15). A Snapshot of the Danish Energy Transition: Objectives, Markets, Grid, Support Schemes and Acceptance. Study. https://orbit.dtu.dk/en/ publications/a-snapshot-of-the-danish-energy-transition-objectives-markets-gri

Schwarz, P. (2012). The art of the long view: planning for the future in an uncertain world. Currency Doubleday.

Shapiro-Bengtsen, S., Andersen, F. M., Münster, M., \& Zou, L. (2020). Municipal solid waste available to the Chinese energy sector - Provincial projections to 2050. Waste Management, 112, 52-65. https://doi.org/10.1016/j.wasman.2020.05.014

The 13th Five-Year Plan for Economic and Social Development of the People's Republic of China, (2O15) (testimony of The Central Committee of the Communist Party of China). https://en.ndrc.gov.cn/policyrelease_8233/201612/ P020191101482242850325.pdf

UNFCC. (2015). Adoption of the Paris agreement. https:// unfccc.int/resource/docs/2015/cop21/eng/IO9rOl.pdf

United Nations. (2020). Accelerating SDG-7 Achievement in the Time of COVID-19.

Wiese, F., Bramstoft, R., Koduvere, H., Pizarro Alonso, A., Balyk, O., Kirkerud, J. G., Tveten, A. G., Bolkesjø, T. F., Münster, M., and Ravn, H. (2018). Balmorel open source energy system model. Energy Strategy Reviews, 20, 26-34. https://doi.org/10.1016/j.esr.2018.01.003

Zhongying, W., and Sandholt, K. (2019). Thoughts on China's energy transition outlook. Energy Transitions, 3(1-2), 59-72. https://doi.org/10.1007/s41825-01900014-w

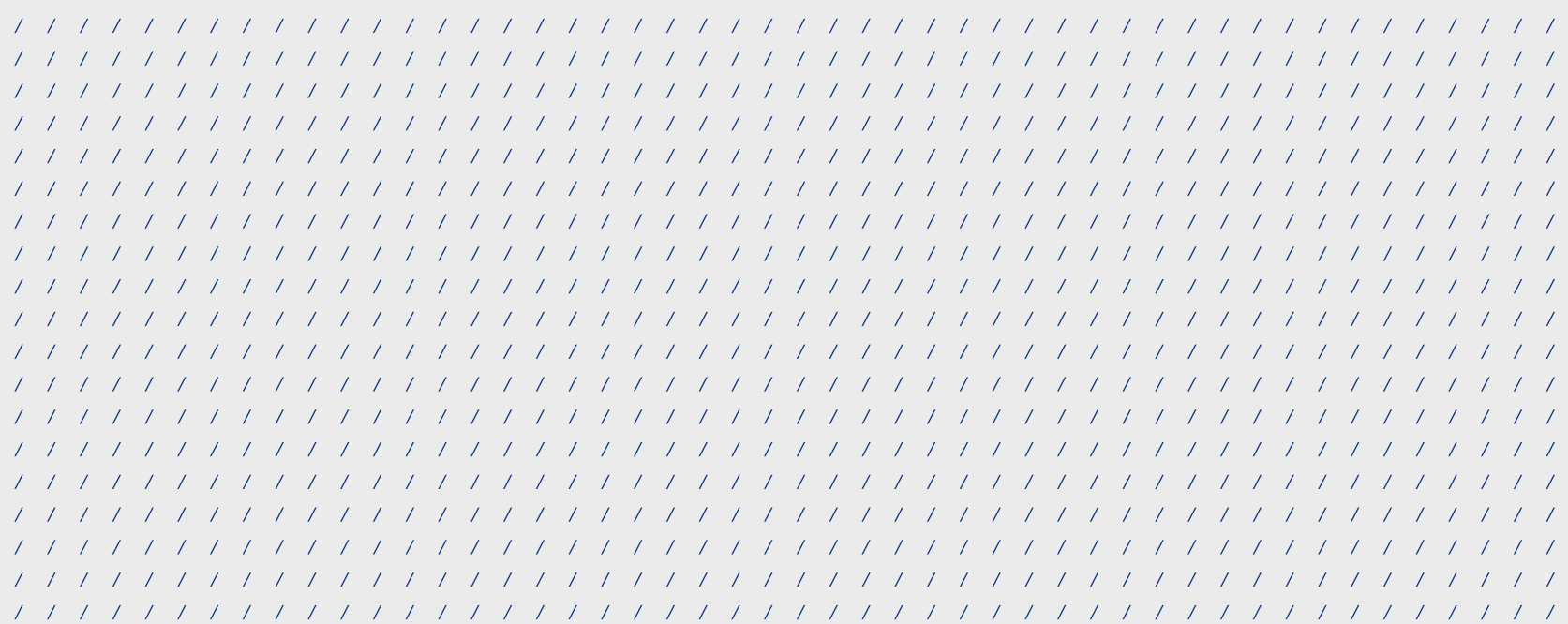

